\title{
A Greater Association of Hyperuricemia than of Metabolic Syndrome with the New Incidence of Chronic Kidney Disease
}

\author{
Satoru Kuriyama ${ }^{1,2 *}$, Shinichiro Nishio' ${ }^{1}$, Satoshi Kidoguchi', Kosuke Honda', \\ Yasuhito Takahashi', Naoki Sugano', Yukio Maruyama', Tatsuo Hosoya ${ }^{3}$, \\ Tomoko Nakano², Tomoko Tanabe ${ }^{2}$, Edward Stim ${ }^{4}$, Takashi Yokoo ${ }^{1}$ \\ ${ }^{1}$ Division of Nephrology \& Hypertension, Department of Medicine, Jikei University, Tokyo, Japan \\ ${ }^{2}$ Health Management Center \& Tokyo Regional Taxation Bureu Clinic, Tokyo, Japan \\ ${ }^{3}$ Department of Pathophysiology \& Therapy in Chronic Kidney Disease, Jikei University School of Medicine, \\ Tokyo, Japan \\ ${ }^{4}$ Emergency Assistance, Japan, Tokyo \\ Email: "kuriyamas218@yahoo.co.jp
}

Received 3 February 2016; accepted 28 March 2016; published 31 March 2016

Copyright (C) 2016 by authors and Scientific Research Publishing Inc.

This work is licensed under the Creative Commons Attribution International License (CC BY).

http://creativecommons.org/licenses/by/4.0/

(c) (i) Open Access

\section{Abstract}

Background: To what extent uric acid (UA) levels and/or metabolic syndrome (Mets) contribute to the onset of chronic kidney disease (CKD) is largely unknown. The present study explores how these two factors have an association with the new incidence of CKD. Methods: Study design is a cohort study. A total of 14,485 participants were eligible for the cross-sectional analysis on UA levels and the prevalence of Mets. Among those individuals, 8,223 participants without CKD and 4,839 without Mets were eligible for the longitudinal analysis of the new incidence of CKD. Parameters monitored were body mass index, systolic and diastolic blood pressure, serum creatinine concentration, estimated glolerular filtration rate, lipid profiles, plasma glucose, $\mathrm{HbA1c}$. The primary predictor was the level of UA and Mets to explain the newly-developed CKD. The observation period was 4 years. Results: In a cross-sectional analysis, higher UA levels were associated with the greater prevalence of Mets. In addition, UA levels were associated with the numbers of the Mets constituents in both genders. In a longitudinal analysis, higher UA levels were associated with the greater rate of CKD and the greater incidence of Mets. In addition, the incidence of CKD at year 4 was influenced by the presence of hyperuricemia, but not by that of the Mets. The odd ratio (OR) to predict the CKD incidence was $1.42(95 \%$ confidence intervals (CI), 0.52 to 3.78) in the presence of Mets alone, $2.10(95 \% \mathrm{CI}, 1.36$ to 3.23 ) in the presence of hyperuricemia alone, and 3.56 (95\% CI, 1.55 to 8.21) in the presence of both. Conclusion: Hyperuricemia has a greater association with the incidence of CKD than Mets does. Hyperuricemia complicated by Mets is additionally detrimental.

${ }^{*}$ Corresponding author.

How to cite this paper: Kuriyama, S., Nishio, S., Kidoguchi, S., Honda, K., Takahashi, Y., Sugano, N., Maruyama, Y., Hosoya, T., Nakano, T., Tanabe, T., Stim, E. and Yokoo, T. (2016) A Greater Association of Hyperuricemia than of Metabolic Syndrome with the New Incidence of Chronic Kidney Disease. Open Journal of Nephrology, 6, 17-27.

http://dx.doi.org/10.4236/ojneph.2016.61003 
Keywords

Uric Acid, Hypertension, CKD, Estimated Glomerular Filtration Rate

\section{Introduction}

Hyperuricemia plays a pivotal role in the progression of chronic kidney disease (CKD), which includes chronic glomerulonephritis [1], diabetic nephropathy [2] [3], gouty kidney [4] [5], all of which frequently leads to end stage renal failure [6] [7]. Of note is that hyperuricemia not only promotes CKD, but also is involved in its early onset [8]-[10]. These data are suggestive of uric acid (UA) as a strong risk factor renal damage, which could eventually lead to the various major cardiovascular events (MACE).

In the last few decades, the metabolic syndrome (Mets) has been increasing in many countries. It is characterized by comorbid conditions such as hypertension, dyslipidemia and diabetes mellitus. Notablely, in the recent clinical guidelines for Mets, hyperuricemia has not been chosen as a constituent of the syndrome [11]. However, physicians are increasingly aware of the strong association of hyperuricemia with the Mets, and both diseases should be clinically intervened in appropriate ways to prevent the upcoming future development of CKD. This context prompted us to investigate to what extent hyperuricemia, in comparison with Mets, contributes to the incident CKD.

In the present trial, we used epidemiological cohorts in a screened population at large to conduct: 1) a crosssectional analysis on the prevalence of Mets according to UA levels; and 2) a longitudinal survey to observe to what extent Mets and hyperuricemia contribute to the new onset of CKD. We applied strict exclusion criteria in order to choose eligible participants.

\section{Subjects \& Methods}

\subsection{Study Population and Methods}

The study design is a retrospective population-based cohort of Japanese office workers aged 25 to 60 years (average $42+/-11$ ), the majority of them were living in the vicinity of Tokyo district. The original number of the participants was 14,485 who had an annual medical check-up starting from 2009 to 2013 in our institutions.

The basic exclusion criteria are individuals receiving medications for diabetes, hyperuricemia, hypertension and dyslipidemia; those having insufficient clinical data; those with past history of incident MACE such as cerebral apoplexy or myocardial infarction; those with any disease requiring hospitalization; those with current cancer or other serious diseases judged by the physicians; and those with current pregnancy. These eliminations leave a total number of 14,485 subjects who are eligible for a cross-sectional analysis of the prevalence of Mets.

For a longitudinal analysis of the effect of either Mets or hyperuricemia, or both on the incidence of CKD, individuals with estimated glomerular filtration rate (eGFR) less than $60 \mathrm{~mL} / \mathrm{min} / 1.73 \mathrm{~m}^{2}$ at entry were also excluded. The present and past history of proteinuria was also another rule out factor. The definition of CKD was a reduction of eGFR less than $60 \mathrm{~mL} / \mathrm{min} / 1.73 \mathrm{~m}^{2}$ at any given time of the observation period of 4 years. This exclusion process finally leaves $8,223 \mathrm{CKD}$-free individuals for the analysis of the new onset of CKD.

A minim requirement of making diagnosis of Mets was defined as individuals with waist circumference $\geq 85$ $\mathrm{cm}$ (if female $90 \mathrm{~cm}$ ), with two or more additional abnormalities including hypertension (blood pressure (BP); $\geq 130 / 85 \mathrm{mmHg}$ ), fasting plasma glucose (FPG; $\geq 110 \mathrm{mg} / \mathrm{dL}$ ), triglyceride (TG; $\geq 150 \mathrm{mg} / \mathrm{dL}$ ) and/or HDL-cholesterol (HDLC; $\leq 40 \mathrm{mg} / \mathrm{dL}$ ). Finally, this exclusion criterion leaves 4839 Mets-free individuals for the new onset of Mets in 4 years time. These subjects are all CKD-free at baseline.

\subsection{Primary Predictor and Outcome}

The primary predictor was the level of UA and Mets to explain the newly-developed CKD. The new incidence of CKD was defined as a decline in eGFR to less than $60 \mathrm{~mL} / \mathrm{min} / 1.73 \mathrm{~m}^{2}$ calculated at any given time of $4 \mathrm{ob}$ servation years [12]. Renal function expressed as eGFR for Japanese was calculated based on the equation; $\mathrm{eGFR}=194 \times \mathrm{Cr}^{-1.094} \times \mathrm{Age}^{-0.287}($ if women $\times 0.739)$, reported elsewhere [13]. 


\subsection{Other Clinical Variables}

Body mass index $(\mathrm{BMI})$ was calculated based on the equation; BMI $=$ Body weight $(\mathrm{BW}) \times 1 /($ Body Height) squared. Laboratory tests were carried out after an 8 to 12 hour fasting. Measurements were made on serum creatinine $(\mathrm{Cr})$ concentration, serum uric acid (UA) concentration, blood urea nitrogen (BUN), electrolytes and lipid profiles including total cholesterol (TC), TG, HDLC, LDL-cholesterol (LDLC), hemoglobin A1c (HbA1c) and fasting plasma glucose (FPG). Hyperuricemia was defined as UA $\geq 7 \mathrm{mg} / \mathrm{dL}$ [14]. Laboratory tests were performed using the Toshiba auto-analyzer (TBA-80 FR neo, Tokyo, Japan). Urinalysis was performed only for qualitative measurement of urinary protein. The value of HbAlc was measured as a unit of JDS (Japan Diabetes Society). Following the worldwide recommendations, all of the HbA1c values was expressed as a unit of NGSP (National glycohemoglobin standardization program) based on the equation; NGSP $(\%)=$ JSD $\times 1.02+0.25$ $(\%)$.

\subsection{Ethical Considerations}

The present study was conducted in accordance with "Recommendations on the Establishment of Animal Experimental Guidelines" approved at the 80th General Assembly of the Japanese Science Council in 1980, and the principles set out in the Declaration of Helsinki 1964 as modified by subsequent version revisions.

The present survey was submitted to the Institutional Review Board (IRB)/Ethics Committee of the Jikei University School of Medicine. After the deliberation the protocol was approved in 2014 by the ethics committee of the University with the clinical trial number 25 - 203 (7338).

\subsection{Statistical Analysis}

The database and all statistical outputs were retained by the Jikei University. Statistical analyses were conducted at the University. The access to the database was limited as deemed necessary. The authors assume full responsibility for the completeness and accuracy of the content of the manuscript.

Cross-sectional analysis on the prevalence of Mets was performed as a function of UA levels by dividing the distribution into 4 UA groups. Cross-sectional associations of Mets and UA levels were performed by using Chi-square analysis for discrete variables, analysis of variance (ANOVA) for continuous variables. The prevalence of Mets in reference to different age groups (Age $<29$ years old, $30-39,40-49,50-59$, and 60<) was analyzed by Mann-Whitney test. For the analyses of Mets constituents and UA levels, after obtaining a statistical significance by ANOVA, Turkey's test was applied to compare the randomly-chosen 2 pair groups.

In the longitudinal analysis, we examined the association of new incident CKD according to UA levels and the presence of Mets. For these outcomes, Cox proportional hazard analysis was used to estimate adjusted odds ratio (OR) and associated $95 \%$ CI. Due to the lack of statistical power in the female cohort, analysis was made on only the males in these longitudinal analyses. Variables significant in univariate analysis were considered to be potential confounders of UA in multivariate models.

Statistical analyses were carried out with Stat Flex version 6.0 (Artec Ltd. Co., Osaka, Japan). Data are presented as the mean $+/-$ standard deviation (SD), unless otherwise indicated. $\mathrm{P} \leq 0.05$ is considered statistically significant. Confidence intervals (CI) are expressed as $95 \%$ CI.

\section{Results}

\subsection{Baseline Characteristics for Cross-Sectional Analysis}

After the exclusion at the start for the cross-sectional analysis, the study cohort had an average age of $42+/-11$ years, an eGFR of $82.0+/-14.6 \mathrm{~mL} / \mathrm{min} / 1.73 \mathrm{~m}^{2}$, an overall UA level of $5.7+/-1.4 \mathrm{mg} / \mathrm{dL}$ (Table 1). Greater UA levels were significantly associated with older age, males, greater prevalence of hypertension, BMI, waist circumference, BMI, SBP, DBP, serum Cr concentration, TC, TG, HDLC, LDLC, FPG, HbAlc and lesser eGFR (ANOVA, $\mathrm{P}<0.001$ ).

\subsection{UA Levels and the Prevalence of Mets}

The prevalence of Mets in male gender was shown in Figure 1. Higher UA levels were associated with the greater prevalence of Mets; the average of respective UA group was $11.3 \%$ (UA $<5 \mathrm{mg} / \mathrm{dL}$ ), $9.7 \%(5.0-5.9$ 
Table 1. Baseline demographics of participants for Mets analyses.

\begin{tabular}{|c|c|c|c|c|c|c|}
\hline \multicolumn{7}{|c|}{ UA Groups (mg/dL) } \\
\hline & Overall & $<5.0$ & $5.0-5.9$ & $6.0-6.9$ & $\geq 7.0$ & \\
\hline $\mathrm{N}$ & 14,485 & 4,096 & 4,060 & 3,809 & 2,520 & \\
\hline Age & $42 \pm 11$ & $40 \pm 11$ & $42 \pm 12$ & $43 \pm 11$ & $44 \pm 10$ & $\mathrm{P}<0.001$ \\
\hline Men (\%) & 79.3 & 44.8 & 86.4 & 96.3 & 98.1 & \\
\hline BMI $\left(\mathrm{Kg} / \mathrm{m}^{2}\right)$ & $23 \pm 4$ & $22 \pm 3$ & $23 \pm 3$ & $24 \pm 3$ & $25 \pm 4$ & $\mathrm{P}<0.001$ \\
\hline Waist circumference $(\mathrm{cm})$ & $81.1 \pm 10.0$ & $76.4 \pm 9.3$ & $80.4 \pm 9.1$ & $83.3 \pm 9.3$ & $86.8 \pm 9.7$ & $\mathrm{P}<0.001$ \\
\hline $\mathrm{SBP}(\mathrm{mmHg})$ & $119 \pm 15$ & $113 \pm 15$ & $119 \pm 14$ & $122 \pm 14$ & $124 \pm 15$ & $\mathrm{P}<0.001$ \\
\hline DBP (mmHg) & $75 \pm 11$ & $71 \pm 11$ & $75 \pm 11$ & $77 \pm 11$ & $80 \pm 11$ & $\mathrm{P}<0.001$ \\
\hline $\mathrm{Cr}(\mathrm{mg} / \mathrm{dL})$ & $0.80 \pm 0.14$ & $0.70 \pm 0.13$ & $0.80 \pm 0.12$ & $0.84 \pm 0.11$ & $0.89 \pm 0.14$ & $\mathrm{P}<0.001$ \\
\hline $\operatorname{eGFR}\left(\mathrm{mL} / \mathrm{min} / 1.73 \mathrm{~m}^{2}\right)$ & $83.0 \pm 14.6$ & $87.6 \pm 15.0$ & $83.7 \pm 13.9$ & $81.0 \pm 13.6$ & $77.2 \pm 13.9$ & $\mathrm{P}<0.001$ \\
\hline $\mathrm{TC}(\mathrm{mg} / \mathrm{dL})$ & $199 \pm 107$ & $193 \pm 31$ & $197 \pm 31$ & $201 \pm 32$ & $210 \pm 33$ & $\mathrm{P}<0.001$ \\
\hline $\mathrm{TG}(\mathrm{mg} / \mathrm{dL})$ & $107 \pm 89$ & $81 \pm 56$ & $100 \pm 93$ & $115 \pm 79$ & $147 \pm 118$ & $\mathrm{P}<0.001$ \\
\hline HDLC (mg/dL) & $61 \pm 15$ & $67 \pm 15$ & $61 \pm 15$ & $59 \pm 15$ & $57 \pm 15$ & $\mathrm{P}<0.001$ \\
\hline LDLC (mg/dL) & $119 \pm 30$ & $111 \pm 28$ & $118 \pm 29$ & $123 \pm 30$ & $129 \pm 31$ & $\mathrm{P}<0.001$ \\
\hline $\mathrm{FPG}(\mathrm{mg} / \mathrm{dL})$ & $96 \pm 18$ & $94 \pm 20$ & $96 \pm 17$ & $97 \pm 17$ & $98 \pm 15$ & $\mathrm{P}<0.001$ \\
\hline HbA1c (NGSP) (\%) & $5.43 \pm 0.59$ & $5.38 \pm 0.64$ & $5.42 \pm 0.58$ & $5.46 \pm 0.57$ & $5.50 \pm 0.55$ & $\mathrm{P}<0.001$ \\
\hline
\end{tabular}

Mets: metabolic syndrome; UA: serum uric acid concentration; BMI: body mass index; SBP: systolic blood pressure; DBP: diastolic blood pressure; Cr: serum creatinine concentration; eGFR: estimated glomerular filtration rate; TC: total cholesterol; TG: triglycerides; HDLC: high-density lipoprotein cholesterol; LDLC: low-densitylipoprotein cholesterol; FPG: fasting plasma glucose concentration; HbAlc: hemoglobin Alc.

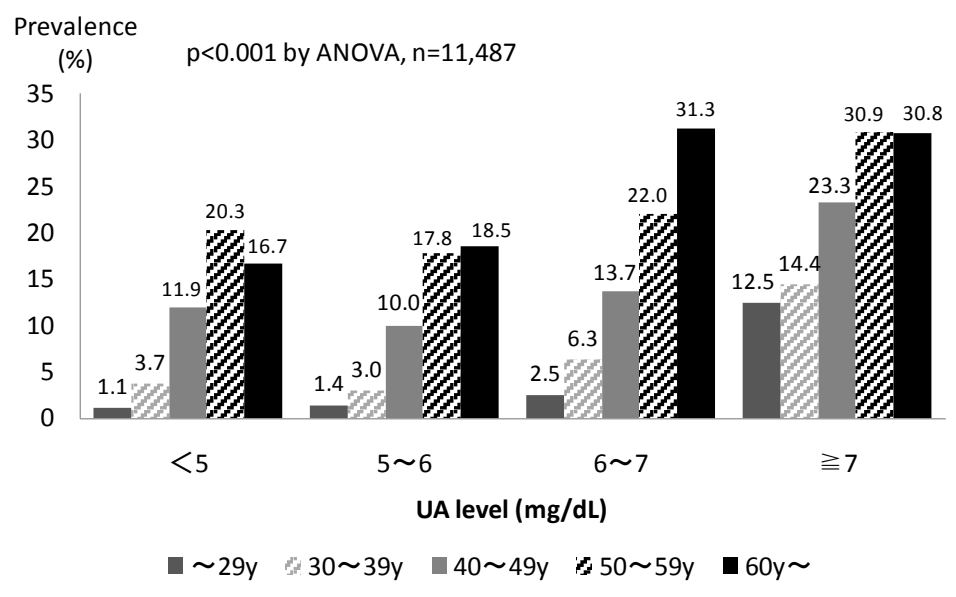

Figure 1. UA levels and the prevalence of Mets (Male only).

$\mathrm{mg} / \mathrm{dL}), 13.9 \%(6.0-6.9 \mathrm{mg} / \mathrm{dL})$ and $23.0 \%(\geq 7 \mathrm{mg} / \mathrm{dL})$, respectively (by the Chi-square test, $\mathrm{P}<0.001)$. In each UA group, there was a statistical difference in the prevalence according to age $(\mathrm{P}<0.01$, by Mann-Whitney test). This increasing trend of the Mets prevalence was prominent in the individual groups with older age.

Figure 2 showed the prevalence of Mets in female gender. Although the magnitude is smaller than male (Figure 1), higher UA levels were also associated with the greater prevalence of Mets; the average value was $0.8 \%(\mathrm{UA}<5 \mathrm{mg} / \mathrm{dL}), 3.6 \%(5.0-5.9 \mathrm{mg} / \mathrm{dL}), 12.9 \%(6.0-6.9 \mathrm{mg} / \mathrm{dL})$ and $23.0 \%(\geq 7 \mathrm{mg} / \mathrm{dL})$, respectively (by the Chi-square test, $\mathrm{P}<0.001$ ). In each UA groups, there was a statistical difference in the prevalence ac- 


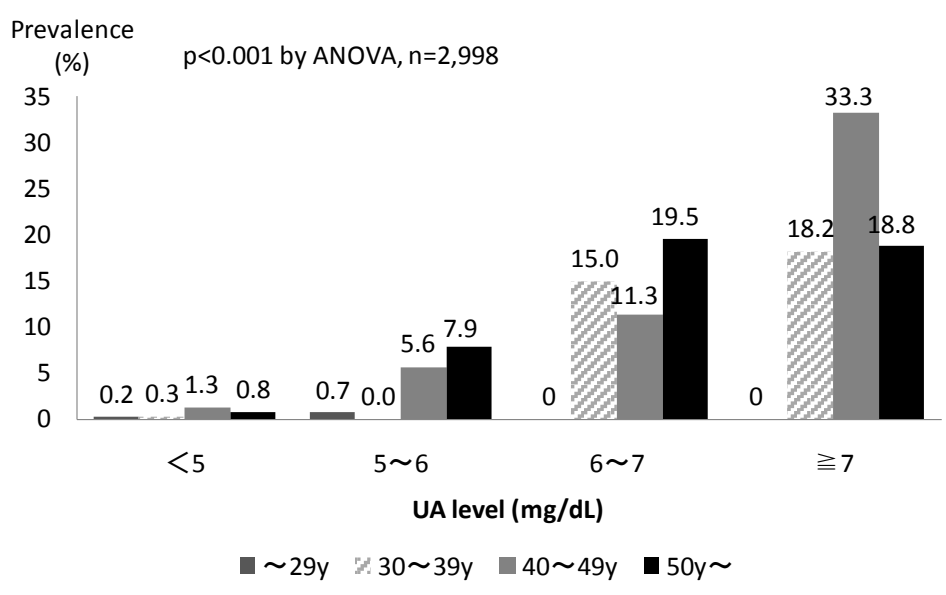

Figure 2. UA levels and the prevalence of Mets (Female only).

cording to age ( $\mathrm{P}<0.01$, by Mann-Whitney test. The increasing trend of the Mets prevalence was prominent in the individual groups with older age.

\subsection{UA Levels and the Mets Constituents}

Figure 3 showed relationship between UA levels and the numbers of Mets constituents, consisting of BP $(\geq 130 / 85 \mathrm{mmHg})$, FPG $(\geq 110 \mathrm{mg} / \mathrm{dL}), \mathrm{TG}(\geq 150 \mathrm{mg} / \mathrm{dL})$ and/or HDLC $(\leq 40 \mathrm{mg} / \mathrm{dL})$ with the minimum requirement of waist circumference (WC) of $\geq 85 \mathrm{~cm}$ (if female $90 \mathrm{~cm}$ ). There was a significant difference among the 5 groups $(\mathrm{P}<0.01$ by AVOVA). Further analyses by Turkey's test showed a strong association between UA levels and the number of the constituents $(\mathrm{P}<0.01$, except for 2 vs 3 constituents, 2 vs 4 constituents and 3 vs 4 constituents).

\subsection{UA Levels and the New Incidence of CKD}

A total of 124 individuals had a decrease in eGFR less than $60 \mathrm{~mL} / \mathrm{min} / 1.73 \mathrm{~m}^{2}$ at year $4(124 / 6,542$ individuals $=2.0 \%)$. Among them, the rate of proteinuria appearance at year 4 was $1.6 \%$ (2/124 individuals). In 124 individuals with CKD at year 4, mean eGFR at baseline and closeout were $67.8+/-7.2$ and $56.2+/-2.5$ $\mathrm{mL} / \mathrm{min} / 1.73 \mathrm{~m}^{2}$, respectively. In contrast, mean eGFR of individuals without $\mathrm{CKD}$ at baseline and closeout were $91.2+/-17.5$ and $83.4+/-13.6 \mathrm{~mL} / \mathrm{min} / 1.73 \mathrm{~m}^{2}(\mathrm{n}=6262)$, respectively.

Table 2 showed demographic findings of CKD free subjects for the CKD incidence. These subjects were followed for 4 years. Figure 4 showed the incident rates of newly developed CKD. Higher UA levels had a close association with new CKD; $1.1 \%$ (UA $<5 \mathrm{mg} / \mathrm{dL}), 1.5 \%(5.0-5.9 \mathrm{mg} / \mathrm{dL}), 1.7 \%(6.0-6.9 \mathrm{mg} / \mathrm{dL}$ ), and 3.4\% $(\geq 7 \mathrm{mg} / \mathrm{dL}$ ), respectively $(\mathrm{P}<0.001$ by the Chi-square test).

\subsection{UA Levels and the Newly Developed Mets}

Table 3 showed Mets free subjects to look into the CKD incidence. Among 4,839 Mets free individuals, 400 individuals $(8 \%=400 / 4,839)$ developed Mets during 4 years time. Figure 5 showed the rates of newly developed Mets, showing that higher UA levels had a close association with the new development of Mets; $3.3 \%$ (UA $<5$ $\mathrm{mg} / \mathrm{dL}), 6.2 \%(5.0-5.9 \mathrm{mg} / \mathrm{dL}), 11.6 \%(6.0-6.9 \mathrm{mg} / \mathrm{dL})$, and $17.1 \%(\geq 7 \mathrm{mg} / \mathrm{dL})$, respectively $(\mathrm{P}<0.001$ by the Chi-square test).

\subsection{The Association of Hyperuricemia and Mets on the CKD Incidence}

After adjustment for age, sex, BMI, waist circumference, systolic BP (SBP), diastolic BP (DBP), TC, TG, HDLC, LDLC, FPG and HbA1c, the multivariate adjusted OR for new-onset of CKD (a decrease in eGFR < 60 $\mathrm{mL} / \mathrm{min} / 1.73 \mathrm{~m}^{2}$ at year 4$)$ in conjunction with hyperuricemia and Mets were calculated in Figure 6. The OR were 1.00 (reference), 1.42 (95\% confidence intervals (CI), 0.52 to 3.78) in the presence of Mets only, 2.10 ( $95 \%$ CI, 1.36 to 3.23 ) in the presence of hyperuricemia only, and 3.56 (95\% CI, 1.55 to 8.21 ) in the presence of 


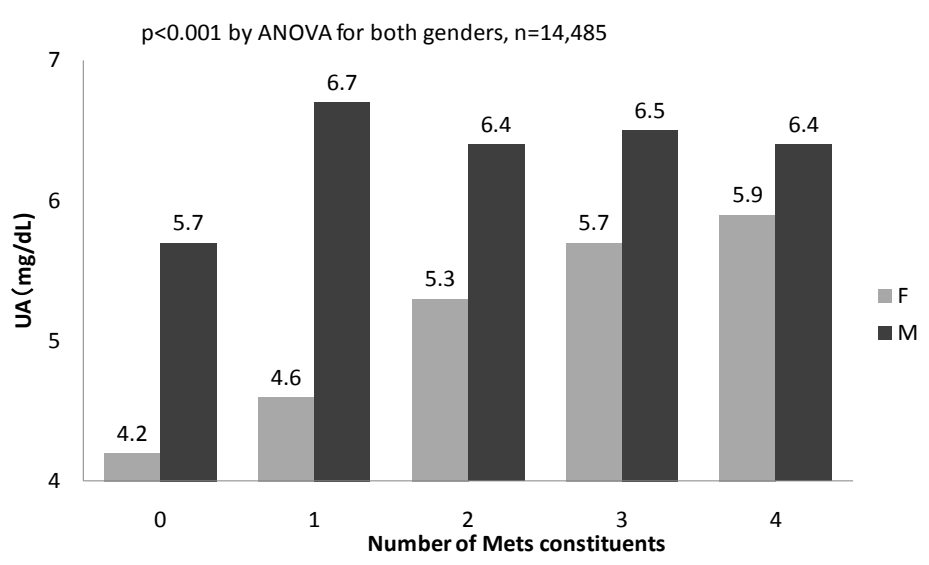

Figure 3. UA levels and the number of Mets constituents.

Table 2. CKD free subjects for the CKD incidence.

\begin{tabular}{|c|c|c|c|c|c|c|}
\hline \multicolumn{7}{|c|}{ UA Groups (mg/dL) } \\
\hline & Overall & $<5.0$ & $5.0-5.9$ & $6.0-6.9$ & $\geq 7.0$ & \\
\hline $\mathrm{N}$ & 8,223 & 2,631 & 2,418 & 2,118 & 1,056 & \\
\hline Age (y) & $39 \pm 10$ & $37 \pm 9$ & $39 \pm 10$ & $40 \pm 10$ & $41 \pm 9$ & $<0.001$ \\
\hline Men (\%) & 77.7 & 42.2 & 89.6 & 97.9 & 98.8 & $<0.001$ \\
\hline Hypertension (\%) & 7.7 & 3.8 & 7.1 & 10.6 & 15.1 & $<0.001$ \\
\hline BMI $\left(\mathrm{Kg} / \mathrm{m}^{2}\right)$ & $22 \pm 3$ & $21 \pm 3$ & $22 \pm 3$ & $23 \pm 3$ & $24 \pm 3$ & $<0.001$ \\
\hline Waist circumference $(\mathrm{cm})$ & $78.6 \pm 8.8$ & $74.1 \pm 8.2$ & $78.6 \pm 7.9$ & $81.1 \pm 7.9$ & $84.2 \pm 8.6$ & $<0.001$ \\
\hline SBP $(\mathrm{mmHg})$ & $118 \pm 13$ & $113 \pm 12$ & $118 \pm 12$ & $120 \pm 13$ & $123 \pm 14$ & $<0.001$ \\
\hline $\mathrm{DBP}(\mathrm{mmHg})$ & $74 \pm 9$ & $70 \pm 9$ & $74 \pm 9$ & $75 \pm 9$ & $77 \pm 9$ & $<0.001$ \\
\hline $\mathrm{Cr}(\mathrm{mg} / \mathrm{dL})$ & $0.75 \pm 0.14$ & $0.65 \pm 0.13$ & $0.77 \pm 0.11$ & $0.80 \pm 0.11$ & $0.83 \pm 0.11$ & $<0.001$ \\
\hline $\operatorname{eGFR}\left(\mathrm{mL} / \mathrm{min} / 1.73 \mathrm{~m}^{2}\right)$ & $91.2 \pm 17.6$ & $96.5 \pm 19.5$ & $91.1 \pm 16.6$ & $88.1 \pm 15.4$ & $84.3 \pm 15.0$ & $<0.001$ \\
\hline $\mathrm{TC}(\mathrm{mg} / \mathrm{dL})$ & $192 \pm 29$ & $187 \pm 29$ & $192 \pm 29$ & $194 \pm 28$ & $201 \pm 28$ & $<0.001$ \\
\hline $\mathrm{TG}(\mathrm{mg} / \mathrm{dL})$ & $94 \pm 59$ & $72 \pm 42$ & $91 \pm 51$ & $106 \pm 65$ & $126 \pm 76$ & $<0.001$ \\
\hline HDLC (mg/dL) & $64 \pm 15$ & $69 \pm 15$ & $64 \pm 15$ & $61 \pm 14$ & $59 \pm 16$ & $<0.001$ \\
\hline LDLC (mg/dL) & $113 \pm 26$ & $106 \pm 25$ & $113 \pm 26$ & $117 \pm 26$ & $122 \pm 27$ & $<0.001$ \\
\hline $\mathrm{FPG}(\mathrm{mg} / \mathrm{dL})$ & $93 \pm 10$ & $91 \pm 9$ & $93 \pm 10$ & $94 \pm 10$ & $96 \pm 11$ & $<0.001$ \\
\hline HbAlc (NGSP) (\%) & $5.23 \pm 0.34$ & $5.21 \pm 0.33$ & $5.23 \pm 0.33$ & $5.25 \pm 0.34$ & $5.29 \pm 0.37$ & $<0.001$ \\
\hline
\end{tabular}

CKD: chronic kidney disease; UA: serum uric acid concentration; BMI: body mass index; SBP: systolic blood pressure; DBP: diastolic blood pressure; Cr: serum creatinine concentration; eGFR: estimated glomerular filtration rate; TC: total cholesterol; TG: triglycerides; HDLC: high-density lipoprotein cholesterol; LDLC: low-densitylipoprotein cholesterol; FPG: fasting plasma glucose concentration; HbA1c: hemoglobin Alc.

both Mets and hyperuricemia. The association of hyperuricemia with the incidence of CKD appeared to be greater than that of the Mets. Moreover, the presence of both has a substantial additive effect on Mets or hyperuricemia alone.

\section{Discussion}

The present study demonstrates that: 1) In a cross-sectional analysis, higher UA levels are associated with the 


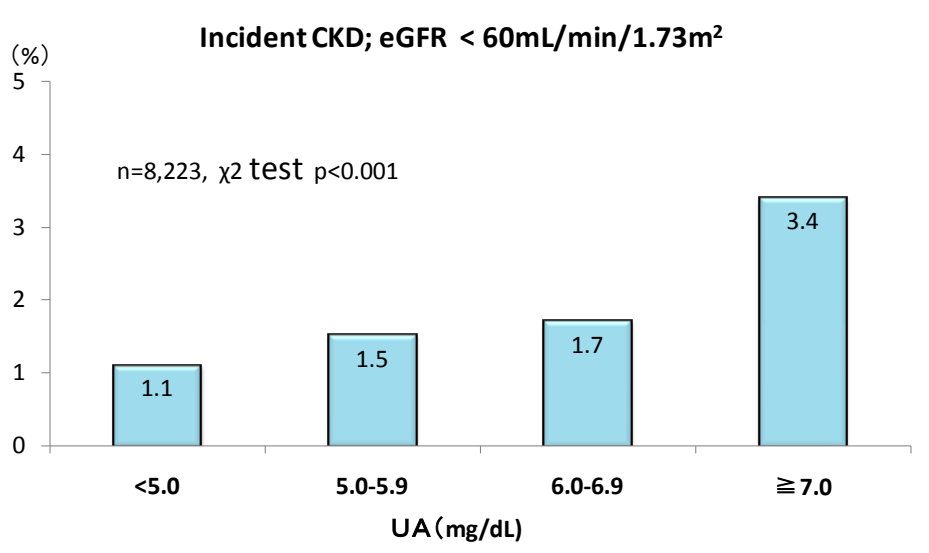

Figure 4. UA levels and the incident CKD at year 4.

Table 3. Mets free subjects for the CKD incidence.

\begin{tabular}{|c|c|c|c|c|c|c|}
\hline \multicolumn{7}{|c|}{ UA Groups (mg/dL) } \\
\hline & Overall & $<5.0$ & $5.0-5.9$ & $6.0-6.9$ & $\geq 7.0$ & \\
\hline $\mathrm{N}$ & 4,839 & 1,440 & 1,446 & 1,297 & 656 & \\
\hline Age (y) & $41 \pm 8$ & $41 \pm 8$ & $42 \pm 8$ & $42 \pm 7$ & $42 \pm 7$ & $<0.001$ \\
\hline Men $(\%)$ & 81.3 & 48.1 & 91.1 & 98.5 & 98.6 & $<0.001$ \\
\hline $\operatorname{BMI}\left(\mathrm{Kg} / \mathrm{m}^{2}\right)$ & $22 \pm 3$ & $21 \pm 3$ & $22 \pm 3$ & $23 \pm 3$ & $24 \pm 3$ & $<0.001$ \\
\hline Waist circumference $(\mathrm{cm})$ & $79.0 \pm 8.3$ & $75.1 \pm 8.0$ & $78.9 \pm 7.7$ & $81.0 \pm 7.4$ & $83.6 \pm 7.8$ & $<0.001$ \\
\hline SBP (mmHg) & $117 \pm 13$ & $113 \pm 12$ & $117 \pm 12$ & $119 \pm 13$ & $121 \pm 13$ & $<0.001$ \\
\hline DBP (mmHg) & $74 \pm 9$ & $71 \pm 9$ & $74 \pm 9$ & $75 \pm 9$ & $76 \pm 9$ & $<0.001$ \\
\hline $\mathrm{Cr}(\mathrm{mg} / \mathrm{dL})$ & $0.76 \pm 0.13$ & $0.68 \pm 0.13$ & $0.78 \pm 0.11$ & $0.81 \pm 0.11$ & $0.83 \pm 0.11$ & $<0.001$ \\
\hline eGFR $\left(\mathrm{mL} / \mathrm{min} / 1.73 \mathrm{~m}^{2}\right)$ & $87.6 \pm 14.9$ & $91.2 \pm 16.1$ & $87.9 \pm 14.5$ & $85.8 \pm 13.7$ & $82.8 \pm 13.1$ & $<0.001$ \\
\hline $\mathrm{TC}(\mathrm{mg} / \mathrm{dL})$ & $194 \pm 29$ & $190 \pm 29$ & $194 \pm 29$ & $196 \pm 28$ & $202 \pm 29$ & $<0.001$ \\
\hline $\mathrm{TG}(\mathrm{mg} / \mathrm{dL})$ & $95 \pm 59$ & $75 \pm 44$ & $93 \pm 50$ & $106 \pm 64$ & $123 \pm 77$ & $<0.001$ \\
\hline $\operatorname{HDLC}(\mathrm{mg} / \mathrm{dL})$ & $64 \pm 16$ & $69 \pm 16$ & $64 \pm 15$ & $61 \pm 14$ & $60 \pm 16$ & $<0.001$ \\
\hline $\mathrm{LDLC}(\mathrm{mg} / \mathrm{dL})$ & $115 \pm 26$ & $109 \pm 25$ & $115 \pm 26$ & $118 \pm 25$ & $123 \pm 27$ & $<0.001$ \\
\hline FPG (mg/dL) & $94 \pm 9$ & $92 \pm 9$ & $94 \pm 9$ & $95 \pm 9$ & $96 \pm 10$ & $<0.001$ \\
\hline HbA1c (NGSP) (\%) & $5.26 \pm 0.3$ & $5.24 \pm 0.30$ & $5.25 \pm 0.30$ & $5.27 \pm 0.29$ & $5.28 \pm 0.33$ & $<0.01$ \\
\hline
\end{tabular}

Mets: metabolic syndrome; UA: serum uric acid concentration; BMI: body mass index; SBP: systolic blood pressure; DBP: diastolic blood pressure; Cr: serum creatinine concentration; eGFR: estimated glomerular filtration rate; TC: total cholesterol; TG: triglycerides; HDLC: high-density lipoprotein cholesterol; LDLC: low-densitylipoprotein cholesterol; FPG: fasting plasma glucose concentration; HbA1c: hemoglobin A1c.

greater prevalence of CKD and Mets; and 2) In a longitudinal analysis, hyperuricemia and Mets are associated with the new incidence of CKD in which the association of the former appears to be substantially greater than that of the latter.

The strengths of this study are the large number of individuals who did not have CKD at the entry, the complete nature of the data set, and the ability to link demographic and clinical factors with CKD. Other advantages include the ability to adjust for multiple factors that may affect initiation of CKD. We must also emphasize that 


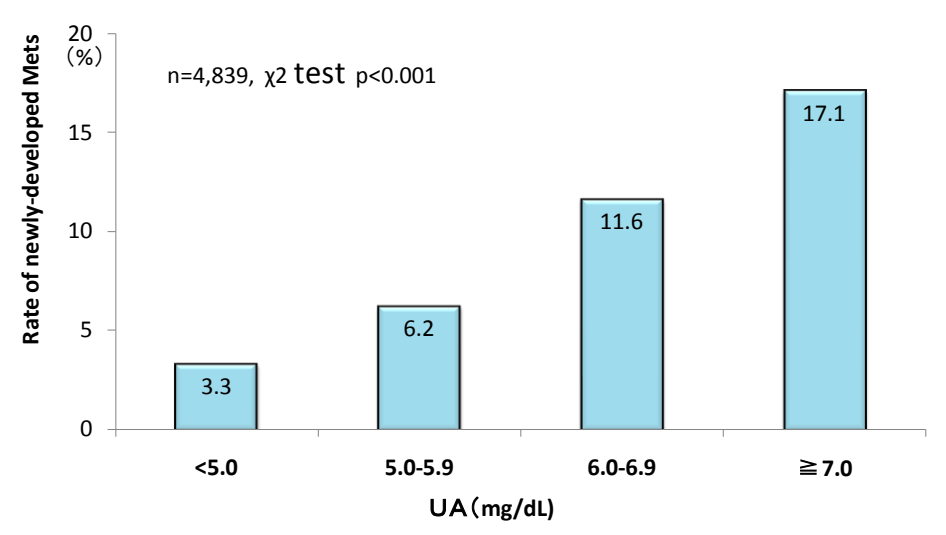

Figure 5. UA levels and newly-developed Mets at year 4.

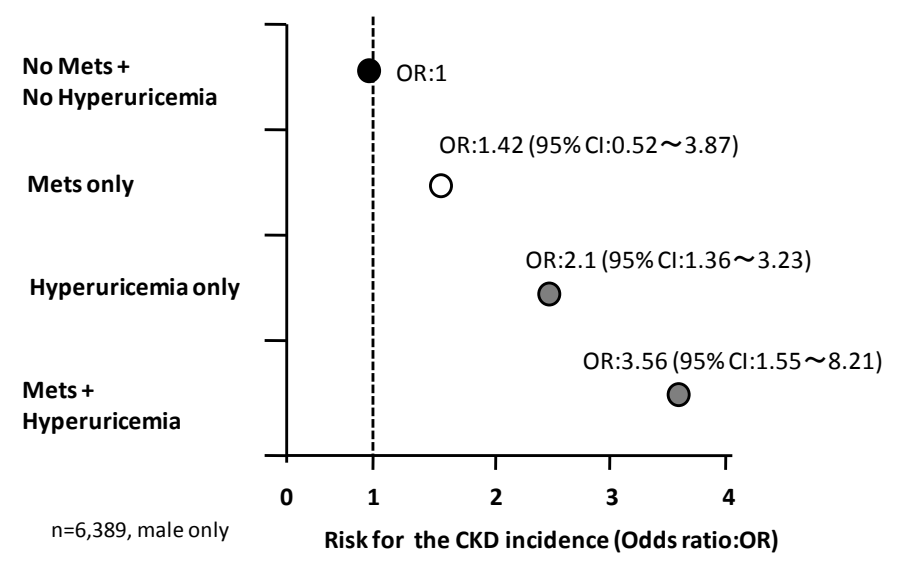

Figure 6. A greater association of hyperuricemia than of Mets with the new incidence of CKD.

we controlled for the currently treated diabetes, hypertension, hyperuricemia, dyslipidemia and MACE etc., all known as well-established predictors of CKD.

To date, a large body of epidemiological trials demonstrates that increased UA is associated with increased risk for future hypertension, diabetic nephropathy and CKD, and that hyperuricemia, per se, could be an independent risk factor for poor cardiovascular prognosis [1]-[10]. In addition, animal experiments demonstrate that increased serum UA causes hypertension that is reversible at the early stage but becomes irreversible at the later stage [15]. Based on these studies, it appears that increased UA represents a possible new and intriguing targetfor the reduction of morbidity and mortality in CKD-associated MACE.

\subsection{UA Levels and the Prevalence of Mets}

Previous reports showed that hyperuricemia is closely related with visceral fat volume and that changes in UA levels are also strongly correlated with changes in the visceral fat volume [16]. Recent clinical trials disclosed that individuals with Mets have a greater UA levels than those without it [17] [18]. Moreover, higher UA levels were closely related with the number of Mets constituents [16] [19] [20]. Taking all of these studies into consideration, the increased UA levels should have been regarded as one of the adjacent factors to the Mets components despite that hyperuricemia's not being included in one of the constituents of Mets according to many guidelines in the world [11].

\subsection{UA Levels with CKD Incidence}

Advanced CKD is a high risk condition, since it frequently induces fatal cardiovascular complications such as MACE [22]. There are mixed literatures on the role of UA level on progression of CKD, with both positive and 
negative results. UA level is an independent risk factor for the progression of kidney disease in a variety of kidney diseases [1]-[10]. Weiner et al. recruited 13,338 participants with intact kidney function in two communitybased cohorts and concluded that elevated UA level is a modest, independent risk factor for incident CKD in the general population [23]. In contrast, Choncol et al. reported that UA level has a minor association with progression of kidney disease and does not appear to be an important risk factor for incident CKD [24]. The present study demonstrates that even without kidney dysfunction, high UA acts as a trigger for new incidence of CKD, suggesting that UA, perse, independent of renal dysfunction has some contribution to declining kidney function.

\subsection{A greater Association of Hyperuricemia than Mets with the CKD Incidence}

Choi et al. reported that the prevalence of the Mets increases substantially with increasing levels of serum UA, suggesting that physicians should recognize the Mets as a frequent comorbidity of hyperuricemia and the treatment of hyperuricemia to prevent serious complications could be crucial [19].

The association of serum UA and Mets with CKD remains controversial. See and associates using data from 81,799 adults with or without Mets (45,148 men and 36,651 women) suggested that hyperuricemia is strongly associated with CKD, independent of the presence of Mets [21]. On the other hand, Hjortnaes et al. showed that although elevated serum UA levels are strongly associated with the Mets, they are as yet not an independent risk factor for vascular disease in patients with the Mets. In patients without Mets, elevated serum UA levels are associated with increased risk for vascular disease [20].

\subsection{Putative Mechanisms of UA Induced CKD}

Although it is beyond the scope of the present study, presuming the mechanism of UA-induced kidney dysfunction is of great interest. Although the entire pathogenesis is largely unknown, the mechanisms by which UA exerts a BP raising effect have been described as a UA-mediated hypertension, which can be highlighted that increase in circulating UA induces vasoconstrictive-hypertension in the early stage and salt sensitive volume- expanded hypertension in the late stage. This is, presumably, via an activation of intra renal renin-angiotensin system, an increased reactive oxygen species, and a decreased nitric oxide production [25]. Studies of humans also found that UA level was an important predictor of both hyperinsulinemia and weight gain [26] [27]. Due to the lack of information, future study must be carried out focusing on whether or not hyperuricemia, perse, affects patients' mortality [28].

\subsection{Limitation of the Study}

Despite the large scale of the data setting, the present study has several limitations. First, the definition of CKD incidence is merely based on changes in eGFR, rather than more precise measures of endogenous Cr clearane. Second, this is a retrospective study in which "Cause \& Effect" is not always appropriately proven. Third, we studied a relatively younger healthy population, which may make it difficult to extrapolate the results to other ill populations. Fourth, residual confounding, by unmeasured factors or by kidney function, could have been present in this analysis. Finally, we did not have information on urine protein excretion, which could have either strengthened or attenuated the results.

\section{Conclusion}

The present study shows that both hyperuricemia and Mets have an impact on the new incidence of CKD. The former appears to be more influential than the latter.

\section{Acknowledgements}

A part of this study was presented at the annual scientific meeting of the Japanese Society of Hypertension held in Ehime Japn in 11 Ocober 2015.

\section{Conflict of Interest}

The authors have declared that no conflict of interest exists. 


\section{References}

[1] Syrjanen, J., Mustonen, J. and Pasternack, A. (2000) Hypertriglyceridaemia and Hyperuricaemia Are Risk Factors for Progression of IgA Nephropathy. Nephrology Dialysis Transplantation, 15, 34-42. http://dx.doi.org/10.1093/ndt/15.1.34

[2] Taniguchi, Y., Hayashi, T., Tsumura, K., Endo, G., Fujii, S. and Okada, K. (2001) Serum Uric Acid and the Risk for Hypertension and Type 2 Diabetes in Japanese Men: The Osaka Health Survey. Journal of Hypertension, 19, 12091215. http://dx.doi.org/10.1097/00004872-200107000-00005

[3] Bo, S., Cavallo-Perin, P., Gentile, L., Repetti, E. and Pagano, G. (2001) Hypouricemia and Hyperuricemia in Type 2 Diabetes: Two Different Phenotypes. European Journal of Clinical Investigation, 31, 318-321. http://dx.doi.org/10.1046/j.1365-2362.2001.00812.x

[4] Fessel, W.J. (1979) Renal Outcomes of Gout and Hyperuricemia. The American Journal of Medicine, 67, 74-82. http://dx.doi.org/10.1016/0002-9343(79)90076-7

[5] Yu, T.F. and Berger, L. (1982) Impaired Renal Function Gout: Its Association with Hypertensive Vascular Disease and Intrinsic Renal Disease. The American Journal of Medicine, 72, 95-100.

[6] Iseki, K., Oshiro, S., Tozawa, M., Iseki, C., Ikemiya, Y. and Takishita, S. (2001) Significance of Hyperuricemia on the Early Detection of Renal Failure in a Cohort of Screened Subjects. Hypertension Research, 24, 691-697. http://dx.doi.org/10.1291/hypres.24.691

[7] Iseki, K., Ikemiya, Y., Inoue, T., Iseki, C., Kinjo, K. and Takishita, S. (2004) Significance of Hyperuricemia as a Risk Factor for Developing ESRD in a Screened Cohort. American Journal of Kidney Diseases, 44, 642-650. http://dx.doi.org/10.1016/S0272-6386(04)00934-5

[8] Johnson, R.J., Segal, M.S., Srinivas, T., Ejaz, A., Mu, W., Roncal, C., Sánchez-Lozada, L.G., Gersch, M., Rodriguez-Iturbe, B., Kang, D.H. and Acosta, J.H. (2005) Essential Hypertension, Progressive Renal Disease, and Uric Acid: A Pathogenetic Link? Journal of the American Society of Nephrology, 16, 1909-1919. http://dx.doi.org/10.1681/ASN.2005010063

[9] Kanellis, J., Feig, D.I. and Johnson, R.J. (2004) Does Asymptomatic Hyperuricaemia Contribute to the Development of Renal and Cardiovascular Disease? An Old Controversy Renewed. Nephrology, 9, 394-399. http://dx.doi.org/10.1111/j.1440-1797.2004.00336.X

[10] Kuriyama, S., Maruyama, Y., Nishio, S., Takahashi, Y., Kidoguchi, S., Kobayashi, C., Takahashi, D., Sugano, N., Hosoya, T. and Yokoo, T. (2015) Serum Uric Acid and the Incidence of CKD and Hypertension. Clinical and Experimental Nephrology, 19, 1127-1134.

[11] Kaur, J. (2014) A Comprehensive Review on Metabolic Syndrome. Cardiology Research and Practice, 2014, Article ID: 943162.

[12] KDIGO (2012) Clinical Practice Guideline for the Evaluation and Management of Chronic Kidney Disease. Chapter 1: Definition and Classification of Chronic Kidney Disease. Kidney International, 3, 5-8.

[13] Matsuo, S., Imai, E., Horio, M., Yasuda, Y., Tomita, K., Nitta, K., Yamagata, K., Tomino, Y., Yokoyama, H. and Hishida, A. (2009) On Behalf of the Collaborators Developing the Japanese Equation for Estimated GFR. Revised Equations for Estimated GFR from Serum Creatinine in Japan. American Journal of Kidney Diseases, 53, 982-992. http://dx.doi.org/10.1053/i.ajkd.2008.12.034

[14] Messerli, F.H., Frohlich, E.D., Dreslinski, G.R., Suarez, D.H. and Aristimuno, G.G. (1980) Serum Uric Acid in Essential Hypertension: An Indicator of Renal Vascular involvement. Annals of Internal Medicine, 93, 817-821. http://dx.doi.org/10.7326/0003-4819-93-6-817

[15] Feig, D.I., Kang, D.H. and Johnson, R.J. (2008) Uric Acid and Cardiovascular Risk. The New England Journal of Medicine, 359, 1811-1821. http://dx.doi.org/10.1056/NEJMra0800885

[16] Tamba, S., Nishizawa, H., Funahashi, T., Okauchi, Y., Ogawa, T., Noguchi, M., Fujita, K., Ryo, M., Kihara, S., Iwahashi, H., Yamagata, K., Nakamura, T., Shimomura, I. and Matsuzawa, Y. (2008) Relationship between the Serum Uric Acid Level, Visceral Fat Accumulation and Serum Adiponectin Concentration in Japanese Men. Internal Medicine, 47, 1175-1180. http://dx.doi.org/10.2169/internalmedicine.47.0603

[17] Lin, B., Shao, L., Luo, Q., Ou-yang, L., Zhou, F., Du, B., He, Q., Wu, J., Xu, N. and Chen, J. (2014) Prevalence of Chronic Kidney Disease and Its Association with Metabolic Diseases: A Cross-Sectional Survey in Zhejiang Province, Eastern China. BMC Nephrology, 15, 36. http://dx.doi.org/10.1186/1471-2369-15-36

[18] Nashar, K. and Egan, B.M. (2014) Relationship between Chronic Kidney Disease and Metabolic Syndrome: Current Perspectives. Diabetes, Metabolic Syndrome and Obesity, 7, 421-435. http://dx.doi.org/10.2147/DMSO.S45183

[19] Choi, H.K. and Ford, E.S. (2007) Prevalence of the Metabolic Syndrome in Individuals with Hyperuricemia. American Journal of Medicine, 120, 442-447. http://dx.doi.org/10.1016/j.amjmed.2006.06.040 
[20] Hjortnaes, J., Algra, A., Olijhoek, J., Huisman, M., Jacobs, J., van der Graaf, Y. and Visseren, F. (2007) Serum Uric Acid Levels and Risk for Vascular Diseases in Patients with Metabolic Syndrome. The Journal of Rheumatology, 34, 1882-1887.

[21] See, L.C., Kuo, C.F., Chuang, F.H., Shen, Y.M., Ko, Y.S., Chen, Y.M. and Yu, K.H. (2011) Hyperuricemia and Metabolic Syndrome: Associations with Chronic Kidney Disease. Clinical Rheumatology, 30, 323-330. http://dx.doi.org/10.1007/s10067-010-1461-z

[22] Go, A.S., Chertow, G.M., Fan, D., McCulloch, C.E. and Hsu, C.Y. (2004) Chronic Kidney Disease and the Risks of Death, Cardiovascular Events, and Hospitalization. The New England Journal of Medicine, 351, 1296-1505. http://dx.doi.org/10.1056/NEJMoa041031

[23] Werner, D.E., Tighiouart, H., Elsayed, E.F., Griffith, J.L., Salem, D.N. and Levey, A.S. (2008) Uric Acid and Incident Kidney Disease in the Community. Journal of the American Society of Nephrology, 19, 1204-1211. http://dx.doi.org/10.1681/ASN.2007101075

[24] Chonchol, M., Shlipak, M.G., Katz, R., Sarnak, M.J., Newman, A.B., Siscovick, D.S., Kestenbaum, B., Carney, J.K. and Fried, L.F. (2007) Relationship of Uric Acid with Progression of Kidney Disease. American Journal of Kidney Diseases, 50, 239-247. http://dx.doi.org/10.1053/j.ajkd.2007.05.013

[25] Cannon, P.J., Stason, W.B., Demartini, F.E., Sommers, S.C. and Laragh, J.H. (1996) Hyperuricemia in Primary and Renal Hypertension. The New England Journal of Medicine, 275, 457-464. http://dx.doi.org/10.1056/NEJM196609012750902

[26] Nakagawa, T., Tuttle, K.R., Short, R.A. and Johnson, R.J. (2005) Fructose-Induced Hyperuricemia as a Causal Mechanism for the Epidemic of the Metabolic Syndrome. Nature Clinical Practice Nephrology, 1, 80-86. http://dx.doi.org/10.1038/ncpneph0019

[27] Masuo, K., Kawaguchi, H., Mikami, H., Ogihara, T. and Tuck, M.L. (2003) Serum Uric Acid and Plasma Norepinephrine Concentrations Predict Subsequent Weight Gain and Blood Pressure Elevation. Hypertension, 42, 474-480. http://dx.doi.org/10.1161/01.HYP.0000091371.53502.D3

[28] Tomita, M., Mizuno, S., Yamanaka, H., Hosoda, Y., Sakuma, K., Matsuoka, Y., Okada, M., Yamaguchi, M., Yosida, H., Morisawa, H. and Murayama, T. (2000) Does Hyperuricemia Affect Mortality? A Prospective Cohort Study of Japanese Male Workers. Journal of Epidemiology, 10, 403-409. http://dx.doi.org/10.2188/jea.10.403 